\title{
Weed infestation and yielding of spring wheat sown in different soil tillage systems
}

\section{Zachwaszczenie a plonowanie pszenicy jarej wysiewanej $w$ różnych systemach uprawy roli}

\author{
Adrian Cyplik $^{1 *}$, Leszek Majchrzak², Jan Bocianowski ${ }^{1}$
}

\section{Summary}

Quantity, species composition and weight of weeds occurring in cropland change mainly due to the applied agrotechnics and natural factors. Specialization in a field of plant production, simplification of crop rotation and an increase in the share of cereal intensified the occurrence of difficult to control weed species. The expansion of weeds in cereal monocultures is already evident in the early stages of cereal development and is more pronounced in spring cereals. The purpose of the research was to indicate the dependence of spring wheat yield on the number and fresh weed weight depending on the share of stubble catch crop in crop rotation and the method of tillage for sowing catch crop and spring wheat. The dominant species were: Capsella bursa-pastoris, Viola arvensis and Chenopodium album. The research results showed that the largest effect of weed quantity and weight on spring wheat yield was observed in the variant with white mustard cultivation as catch crop after subsoiling and on which wheat was sown in a direct sowing technology (the average number of weeds was $15.4 \mathrm{pcs} / \mathrm{m}^{2}$, and their mass $\left.22.0 \mathrm{~g} / \mathrm{m}^{2}, \mathrm{R}^{2}=79.3 \%\right)$. The significance of the effect of weed mass and quantity on spring wheat yield has not been proven, when both white mustard and spring wheat were sown after cultivating the soil with an aggregate.

Key words: weeds, spring wheat, cover crop, determination coefficient

\section{Streszczenie}

Liczebność i skład gatunkowy oraz wielkość masy chwastów występujących w zbiorowiskach pól uprawnych zmieniają się głównie pod wpływem stosowanej agrotechniki i czynników przyrodniczych. Specjalizacja produkcji roślinnej, uproszczenie płodozmianów i wzrost udziału w nich roślin zbożowych nasiliły występowanie gatunków chwastów trudnych do zwalczania. Ekspansja chwastów w monokulturach zbożowych zaznacza się już w początkowych stadiach rozwoju zbóż i mocniej ujawnia się w zbożach jarych. Celem przeprowadzonych badań było wskazanie wpływu liczby i świeżej masy chwastów na plonowanie pszenicy jarej w zależności od udziału międzyplonu ścierniskowego w zmianowaniu oraz sposobu uprawy roli pod wysiew międzyplonu i pszenicy jarej. Gatunkami dominującymi były: Capsella bursa-pastoris, Viola arvensis i Chenopodium album. Na podstawie przeprowadzonych badań wykazano, że największy wpływ liczby i masy chwastów na plon pszenicy jarej zaobserwowano w wariancie z uprawą gorczycy białej w międzyplonie ścierniskowym po podorywce oraz w wariancie, gdzie pszenicę wysiewano w technologii siewu bezpośredniego (średnia liczba chwastów wynosiła $15,4 \mathrm{szt} . / \mathrm{m}^{2}$, a ich masa $22,0 \mathrm{~g} / \mathrm{m}^{2}, \mathrm{R}^{2}=79,3 \%$ ). Nie udowodniono istotnego wpływu masy i liczby chwastów na plonowanie pszenicy jarej, gdy zarówno gorczycę białą, jak i pszenicę jarą wysiewano po wcześniejszej uprawie gleby agregatem.

Słowa kluczowe: chwasty, pszenica jara, międzyplon, współczynnik determinacji

\footnotetext{
${ }^{1}$ Uniwersytet Przyrodniczy w Poznaniu, Katedra Metod Matematycznych i Statystycznych Wojska Polskiego 28, 60-637 Poznań

2Uniwersytet Przyrodniczy w Poznaniu, Katedra Agronomii, Dojazd 11, 60-632 Poznań

*corresponding author: adrian.cyplik@up.poznan.pl

${ }^{1}$ ORCID: 0000-0002-9753-9277, 0000-0002-0102-0084

2ORCID: 0000-0002-1593-491X
} 


\section{Wstęp / Introduction}

Liczebność i skład gatunkowy oraz wielkość masy chwastów występujących w zbiorowiskach pól uprawnych zmieniają się głównie pod wpływem stosowanej agrotechniki i czynników przyrodniczych (Parylak i wsp. 2006; Sekutowski i Domaradzki 2009). Specjalizacja produkcji roślinnej, uproszczenie płodozmianów i wzrost udziału w nich roślin zbożowych nasiliły występowanie gatunków chwastów trudnych do zwalczania. Jak wskazują Kwiatkowski i wsp. (2004) ekspansja chwastów w monokulturach zbożowych uzależniona jest od okresu ich trwania i silniej ujawnia się w zbożach jarych. Liczba i masa chwastów często determinowane są przez sposób uprawy roli pod wysiew gatunku uprawianego w plonie głównym (Skuterud i wsp. 1996; Tørresen i Skuterud 2002; Kraska i Pałys 2006; Woźniak 2011; Majchrzak i Piechota 2014), a także międzyplonu (Gawęda 2009; Gawęda i Kwiatkowski 2012; Didon i wsp. 2014; Gawęda i wsp. 2014; Żuk-Gołaszewska i wsp. 2019).

Celem przeprowadzonych badań było określenie plonowania pszenicy jarej w zależności od liczby i świeżej masy chwastów, udziału międzyplonu ścierniskowego w zmianowaniu oraz sposobu uprawy roli pod wysiew międzyplonu i pszenicy jarej.

\section{Materiały i metody / Materials and methods}

W latach 2011-2013 w Zakładzie Doświadczalno-Dydaktycznym w Brodach (52 $\left.26^{\circ} \mathrm{N}, 16^{\circ} 17^{\prime} \mathrm{E}\right)$ należącym do Uniwersytetu Przyrodniczego w Poznaniu przeprowadzono dwuczynnikowe doświadczenie polowe w czterech powtórzeniach w uprawie pszenicy jarej. Czynnikiem I rzędu była uprawa międzyplonu ścierniskowego. Gorczycę białą odmiany Nakielska w ilości $20 \mathrm{~kg} / \mathrm{ha}$ wysiano w II dekadzie sierpnia. Rozpatrywano trzy poziomy tego czynnika: a) uprawa pszenicy jarej bez międzyplonu, b) uprawa pszenicy po międzyplonie wysiewanym po podorywce, c) uprawa pszenicy po międzyplonie wysianym $\mathrm{w}$ siewie bezpośrednim. Czynnikiem II rzędu był sposób uprawy pszenicy jarej odmiany Vinjet wysiewanej corocznie na tym samym polu w zakładanej obsadzie 400 ziaren na $1 \mathrm{~m}^{2}$ (termin siewu: III dekada marca, I dekada kwietnia). Badano trzy warianty uprawy: a) siew bezpośredni, b) uprawa uproszczona (agregat uprawowy), c) uprawa płużna. Eksperyment zlokalizowano na glebie płowej o składzie granulometrycznym piasku gliniastego lekkiego płytko zalegającego na glebie lekkiej. Zaliczono ją do klasy bonitacyjnej IVb kompleksu żytniego bardzo dobrego. Gleba wykazywała odczyn obojętny (pH w $1 \mathrm{~mol} \mathrm{KCl}=6,7$ do 7,2).

Ziarno pszenicy jarej zbierano kombajnem poletkowym z powierzchni $20 \mathrm{~m}^{2}$ i przeliczono na t/ha. Analizę zachwaszczenia pszenicy jarej wykonywano corocznie na wyznaczonych losowo częściach poletek doświadczalnych przykrywanych foliowymi osłonami podczas wykonywania zabiegu odchwaszczania. $\mathrm{W}$ fazie rozwojowej $\mathrm{BBCH}$ 31-32 pszenicy jarej określano na powierzchni $1 \mathrm{~m}^{2}$ świeżą masę i liczbę chwastów z uwzględnieniem ich składu botanicznego.

Różnice pomiędzy poszczególnymi grupami doświadczalnymi dla plonu, liczby oraz masy chwastów oraz różnice w liczbie oraz masie chwastów w trzech latach prowadzenia doświadczenia, wykazano za pomocą analizy wariancji oraz testu HSD Tukey'a. Wpływ liczby chwastów oraz ich masy (rozpatrywanych ogólnie dla wszystkich gatunków) na plon pszenicy jarej (w zależności od udziału międzyplonu ścierniskowego $\mathrm{w}$ zmianowaniu oraz sposobu uprawy roli pod wysiew międzyplonu) oceniano z wykorzystaniem modelu regresji liniowej.

\section{Wyniki i dyskusja / Results and discussion}

Gatunkami dominującymi w odniesieniu do liczby chwastów były: Capsella bursa-pastoris, Viola arvensis i Chenopodium album. W mniejszym nasileniu występowaty także: Stellaria media, Cirsium arvense, Descurainia sophia oraz Erigeron canadensis. Stwierdzono istotne różnice pomiędzy liczbą oraz masą chwastów na przestrzeni trzech lat prowadzenia doświadczenia. Różnice zaobserwowano pomiędzy liczbą chwastów w 2011, a 2012 i 2013 roku (średnio o 40,5 szt. $/ \mathrm{m}^{2}$ ) oraz masą chwastów pomiędzy obserwacjami z roku 2013, a 2011 i 2012 (średnio o $62,6 \mathrm{~g} / \mathrm{m}^{2}$ ). Nie stwierdzono istotnych różnic w plonie na przestrzeni lat.

Plon pszenicy jarej różnił się istotnie w zależności od stosowanych sposobów uprawy roli i międzyplonu (rys. 1). Największą, istotną różnicę wykazano pomiędzy uprawą pszenicy w siewie bezpośrednim bez zastosowania międzyplonu (Z_D; 2,93 t/ha), a z siewem bezpośrednim międzyplonu i uprawą płużną pod wysiew pszenicy jarej (N_P; $3,74 \mathrm{t} / \mathrm{ha}$ ) (rys. 1). Istotne różnice pomiędzy poziomami analizowanych czynników doświadczenia zaobserwowano również $\mathrm{w}$ odniesieniu do średniej liczby chwastów (rys. 2). Największą liczbę chwastów zaobserwowano w wariancie z uprawą gorczycy białej w międzyplonie ścierniskowym po podorywce oraz wysiewem pszenicy po uprawie orkowej (S P; 163,9 szt. $/ \mathrm{m}^{2}$ ). Najmniejszą średnią ich liczbę uzyskano po zastosowaniu tego samego międzyplonu, wysiewanego $\mathrm{w}$ technologii siewu bezpośredniego (N_D; 15,4 szt. $/ \mathrm{m}^{2}$ ) (rys. 2). Podobnie Jaskulski i wsp. (2000) odnotowali wzrost liczby chwastów w jęczmieniu jarym wysiewanym po międzyplonach z gorczycy białej i rzepaku ozimego odpowiednio o 6 i 15\%. Odmienne rezultaty uzyskała Gawęda (2009), w badaniach której wysiewane międzyplony gorczycy białej, facelii błękitnej, rzepaku ozimego oraz mieszanki roślin strączkowych (łubin wąskolistny, groch 


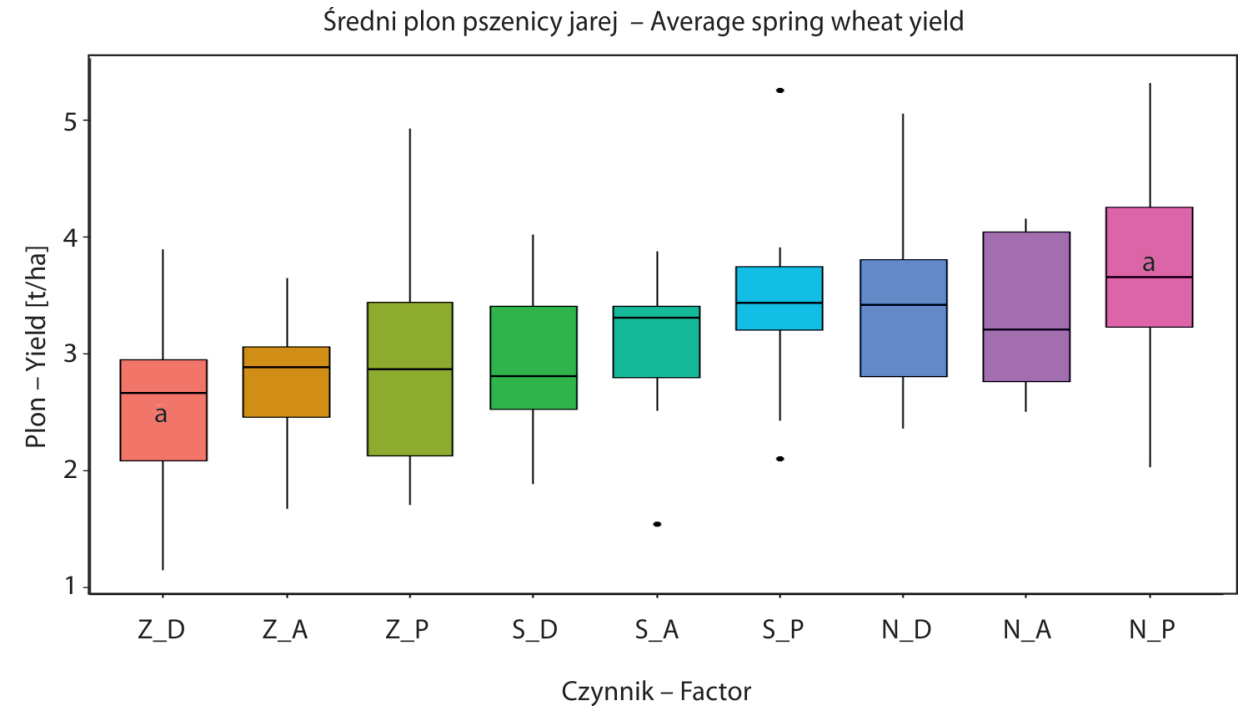

Rys. 1. Wykres pudełkowy obrazujący plon ziarna pszenicy jarej w zależności od zastosowanego międzyplonu i sposobu uprawy roli Fig. 1. Chart box depict spring wheat grain yield depend on cover crop and method of soil tillage

Z_D - obiekt bez międzyplonu, a pszenica wysiana technologią siewu bezpośredniego - without cover crop, wheat sown in direct sowing technology, Z_A - obiekt bez międzyplonu, a pszenica wysiana na glebie uprawianej agregatem - without cover crop, wheat sown in soil cultivated with aggregate, Z_P - obiekt bez międzyplonu, a pszenica wysiana na uprawie płużnej - without cover crop, wheat sown after plough tillage, S_D - międzyplon wysiany po podorywce, a pszenica wysiana technologią siewu bezpośredniego - cover crop sown after skimming, wheat sown in direct sowing technology, S_A - międzyplon wysiany po podorywce, a pszenica wysiana na glebie uprawianej agregatem - cover crop sown after skimming, wheat sown in soil cultivated with aggregate, S_P - międzyplon wysiany po podorywce, a pszenica wysiana na uprawie płużnej - cover crop sown after skimming, wheat sown after plough tillage, N_D - międzyplon wysiany technologią siewu bezpośredniego oraz pszenica wysiana technologią siewu bezpośredniego - cover crop sown in direct sowing technology, wheat sown in direct sowing technology, N_A - międzyplon wysiany technologią siewu bezpośredniego, a pszenica wysiana na glebie uprawianej agregatem - cover crop sown in direct sowing technology, wheat sown in soil cultivated with aggregate, N_P - międzyplon wysiany technologią siewu bezpośredniego, a pszenica wysiana na uprawie płużnej - cover crop sown in direct sowing technology, wheat sown after plough tillage Literami oznaczono istotne różnice pomiędzy grupami - Letters show significant difference between group

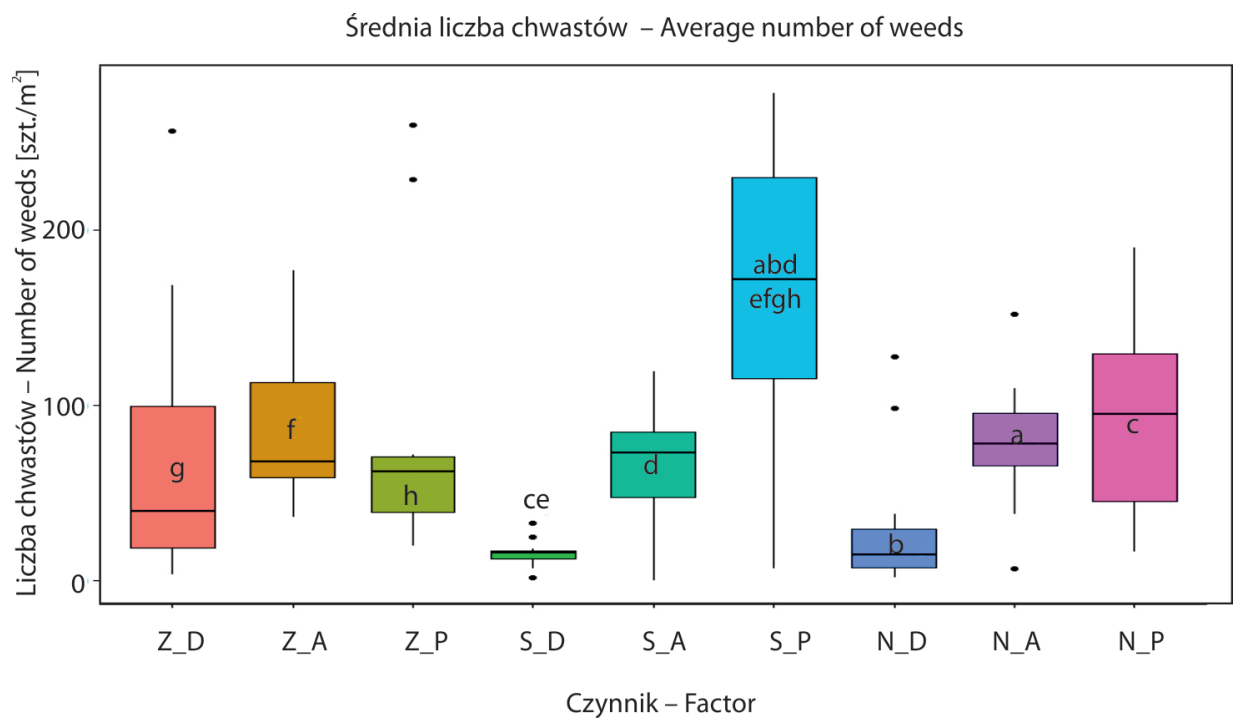

Rys. 2. Wykres pudełkowy obrazujący średnią liczbę chwastów w zależności od zastosowanego międzyplonu i sposobu uprawy Fig. 2. Chart box depict average number of weeds depend on cover crop and method of soil

Z D - obiekt bez międzyplonu, a pszenica wysiana technologią siewu bezpośredniego - without cover crop, wheat sown in direct sowing technology, Z_A - obiekt bez międzyplonu, a pszenica wysiana na glebie uprawianej agregatem - without cover crop, wheat sown in soil cultivated with aggregate, Z_P - obiekt bez międzyplonu, a pszenica wysiana na uprawie płużnej - without cover crop, wheat sown after plough tillage, S_D - międzyplon wysiany po podorywce, a pszenica wysiana technologią siewu bezpośredniego - cover crop sown after skimming, wheat sown in direct sowing technology, S A - międzyplon wysiany po podorywce, a pszenica wysiana na glebie uprawianej agregatem - cover crop sown after skimming, wheat sown in soil cultivated with aggregate, S_P - międzyplon wysiany po podorywce, a pszenica wysiana na uprawie płużnej - cover crop sown after skimming, wheat sown after plough tillage, N_D - międzyplon wysiany technologią siewu bezpośredniego oraz pszenica wysiana technologią siewu bezpośredniego - cover crop sown in direct sowing technology, wheat sown in direct sowing technology, N_A - międzyplon wysiany technologią siewu bezpośredniego, a pszenica wysiana na glebie uprawianej agregatem - cover crop sown in direct sowing technology, wheat sown in soil cultivated with aggregate, N_P - międzyplon wysiany technologią siewu bezpośredniego, a pszenica wysiana na uprawie płużnej - cover crop sown in direct sowing technology, wheat sown after plough tillage Literami oznaczono istotne różnice pomiędzy grupami - Letters show significant difference between group 


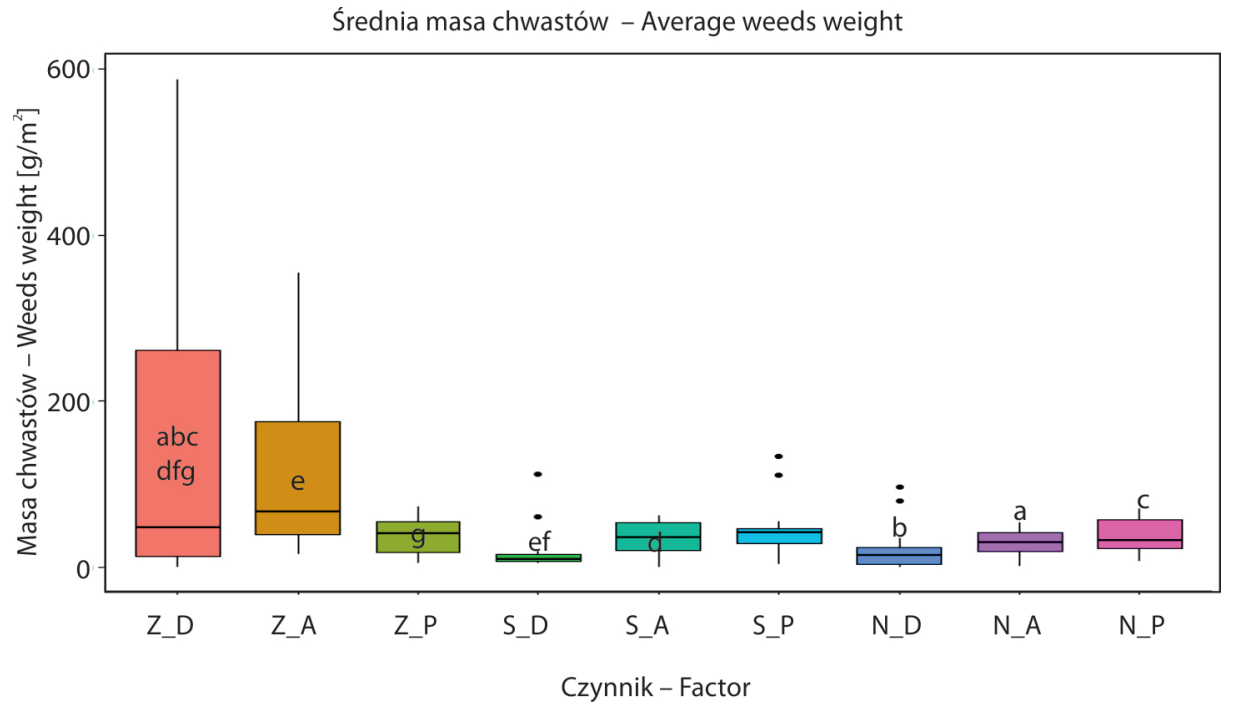

Rys. 3. Wykres pudełkowy obrazujący średnią masę chwastów w zależności od zastosowanego międzyplonu i sposobu uprawy

Fig. 3. Chart box depict average weight of weeds depend on cover crop and method of soil tillage

Z_D - obiekt bez międzyplonu, a pszenica wysiana technologią siewu bezpośredniego - without cover crop, wheat sown in direct sowing technology, Z_A - obiekt bez międzyplonu, a pszenica wysiana na glebie uprawianej agregatem - without cover crop, wheat sown in soil cultivated with aggregate, Z_P - obiekt bez międzyplonu, a pszenica wysiana na uprawie płużnej - without cover crop, wheat sown after plough tillage, S_D - międzyplon wysiany po podorywce, a pszenica wysiana technologią siewu bezpośredniego - cover crop sown after skimming, wheat sown in direct sowing technology, S_A-międzyplon wysiany po podorywce, a pszenica wysiana na glebie uprawianej agregatem - cover crop sown after skimming, wheat sown in soil cultivated with aggregate, S_P - międzyplon wysiany po podorywce, a pszenica wysiana na uprawie płużnej - cover crop sown after skimming, wheat sown after plough tillage, N_D - międzyplon wysiany technologią siewu bezpośredniego oraz pszenica wysiana technologią siewu bezpośredniego - cover crop sown in direct sowing technology, wheat sown in direct sowing technology, N_A - międzyplon wysiany technologią siewu bezpośredniego, a pszenica wysiana na glebie uprawianej agregatem - cover crop sown in direct sowing technology, wheat sown in soil cultivated with aggregate, N_P - międzyplon wysiany technologią siewu bezpośredniego, a pszenica wysiana na uprawie płużnej - cover crop sown in direct sowing technology, wheat sown after plough tillage Literami oznaczono istotne różnice pomiędzy grupami - Letters show significant difference between group

Tabela 1. Wyniki analizy regresji wpływu liczby oraz świeżej masy chwastów na plon pszenicy jarej niezależnie dla każdej z grup międzyplonu oraz sposobu uprawy roli

Table 1. Results of regression analysis of influence number and fresh weight of weeds on spring wheat yield independence for cover crop and methods of soil tillage

\begin{tabular}{|c|c|c|c|c|}
\hline $\begin{array}{l}\text { Liczba chwastów } \\
\text { Number of weeds }\end{array}$ & $\begin{array}{l}\text { Świeża masa chwastów } \\
\text { Fresh weight of weeds }\end{array}$ & $\begin{array}{l}\text { Międzyplon ścierniskowy } \\
\text { Cover crop }\end{array}$ & $\begin{array}{l}\text { Sposób uprawy roli } \\
\text { Method of soil tillage }\end{array}$ & $\begin{array}{c}\mathrm{R}^{2} \\
{[\%]} \\
\end{array}$ \\
\hline 0,014 & 0,003 & $\begin{array}{l}\text { bez międzyplonu } \\
\text { without cover crop }\end{array}$ & $\begin{array}{l}\text { siew bezpośredni } \\
\text { direct sowing }\end{array}$ & $60,77 \%$ \\
\hline $0,021 * *$ & 0,005 & $\begin{array}{l}\text { bez międzyplonu } \\
\text { without cover crop }\end{array}$ & $\begin{array}{l}\text { agregat uprawowy } \\
\text { aggregate }\end{array}$ & $89,22 \%$ \\
\hline 0,012 & 0,033 & $\begin{array}{l}\text { bez międzyplonu } \\
\text { without cover crop }\end{array}$ & $\begin{array}{l}\text { uprawa płużna } \\
\text { plough tillage }\end{array}$ & $72,90 \%$ \\
\hline $0,138^{* *}$ & 0,009 & $\begin{array}{l}\text { podorywka } \\
\text { skimming }\end{array}$ & $\begin{array}{l}\text { siew bezpośredni } \\
\text { direct sowing }\end{array}$ & $79,29 \%$ \\
\hline 0,026 & 0,027 & $\begin{array}{l}\text { podorywka } \\
\text { skimming }\end{array}$ & $\begin{array}{l}\text { agregat uprawowy } \\
\text { aggregate }\end{array}$ & $86,58 \%$ \\
\hline $0,019 * *$ & $-0,005$ & $\begin{array}{l}\text { podorywka } \\
\text { skimming }\end{array}$ & $\begin{array}{l}\text { uprawa płużna } \\
\text { plough tillage }\end{array}$ & $85,56 \%$ \\
\hline 0,030 & 0,019 & $\begin{array}{l}\text { siew bezpośredni } \\
\text { direct sowing }\end{array}$ & $\begin{array}{l}\text { siew bezpośredni } \\
\text { direct sowing }\end{array}$ & $36,95 \%$ \\
\hline 0,024 & 0,030 & $\begin{array}{l}\text { siew bezpośredni } \\
\text { direct sowing }\end{array}$ & $\begin{array}{l}\text { agregat uprawowy } \\
\text { aggregate }\end{array}$ & $81,29 \%$ \\
\hline 0,015 & $0,047^{*}$ & $\begin{array}{l}\text { siew bezpośredni } \\
\text { direct sowing }\end{array}$ & $\begin{array}{l}\text { uprawa płużna } \\
\text { plough tillage }\end{array}$ & $86,64 \%$ \\
\hline
\end{tabular}

$* \mathrm{p}<0,05-\mathrm{p}<0.05, * * \mathrm{p}<0,01-\mathrm{p}<0.01$

$\mathrm{R}^{2}$ - współczynnik determinacji - coefficient of determination 
pastewny) nie wpływały istotnie na zróżnicowanie liczby chwastów w łanie jęczmienia jarego. Z kolei Kwiatkowski (2004) uzyskał istotny spadek masy chwastów w jęczmieniu jarym po przyoraniu gorczycy i mieszanki strączkowych. W badaniach własnych średnia masa chwastów różniła się istotnie w zależności od zastosowanych czynników doświadczenia (rys. 3). Największą zaobserwowaną średnią masą chwastów charakteryzował się obiekt, na którym pszenicę uprawiano $\mathrm{w}$ siewie bezpośrednim bez wysiewu międzyplonu (Z_D; 37,7 g/m²), natomiast najmniejszą, gdy gorczycę białą wysiewano w międzyplonie ścierniskowym po podorywce i pszenicę jarą w siewie bezpośrednim (S_D; $\left.22,0 \mathrm{~g} / \mathrm{m}^{2}\right)$ (rys. 3).

$\mathrm{Na}$ podstawie wyników uzyskanych $\mathrm{z}$ przeprowadzonych badań wykazano, że największy wpływ liczby chwastów (rozpatrywanych ogólnie dla wszystkich gatunków) na plon pszenicy jarej zaobserwowano w wariancie $\mathrm{z}$ uprawą gorczycy białej w międzyplonie ścierniskowym po podorywce oraz $\mathrm{w}$ wariancie, w którym pszenicę wysiewano $\mathrm{w}$ technologii siewu bezpośredniego (S_D; średnia liczba chwastów wynosiła $15,4 \mathrm{szt} . / \mathrm{m}^{2}$, ich masa 22,0 g/m², a współczynnik determinacji modelu [R $\left.\mathrm{R}^{2}\right]$ wynosił 79,3\%) (tab. 1). W badaniach Gawędy (2009) wysiew międzyplonu po podorywce powodował zwiększenie masy chwastów średnio o $14,6 \% \mathrm{w}$ porównaniu do stwierdzonego na obiektach $\mathrm{z}$ jego siewem bezpośrednim. Istotnym wpływem liczby chwastów na plon pszenicy charakteryzowały się również uprawy bez stosowania międzyplonu, gdzie pszenicę wysiewano po uprawie gleby agregatem $\left(Z_{-} \mathrm{A} ; \mathrm{R}^{2}=89,2 \%\right)$ oraz $\mathrm{z}$ zastosowaniem międzyplonu ścierniskowego po podorywce i siewie pszenicy po uprawie płużnej (S_P; $\mathrm{R}^{2}=85,6 \%$ ) (tab. 1). Istotny wpływ masy chwastów zaobserwowano jedynie w jednej grupie, gdzie międzyplon wysiano tech- nologią siewu bezpośredniego, a pszenicę po uprawie płużnej (D_P; $\mathrm{R}^{2}=86,6 \%$ ) (tab. 1).

$\mathrm{W}$ badaniach własnych nie udowodniono istotności wpływu masy i liczby chwastów na plonowanie pszenicy jarej, gdy zarówno gorczycę białą, jak i pszenicę jarą wysiewano po wcześniejszej uprawie gleby agregatem (tab. 1).

\section{Wnioski / Conclusions}

1. Uzyskane wyniki regresji liniowej, pozwoliły stwierdzić wpływ liczby chwastów na kształtowanie wielkości plonu pszenicy $w$ trzech grupach badawczych (Z_A, S_D, S_P) oraz masy chwastów dla jednej grupy (D_P). Wyniki pozostałych grup nie zostały potwierdzone statystycznie.

2. Uzyskane wyniki badań wskazują na istotność różnic w plonie, liczbie oraz masie chwastów w odniesieniu do analizowanych poziomów czynników doświadczalnych, co sugeruje istotny wpływ międzyplonu oraz sposobów uprawy roli na plon ziarna, liczbę i masę chwastów.

3. Zauważono tendencję wzrostu plonu wraz ze zmniejszaniem się średniej masy chwastów. Różnic tych jednak nie udowodniono statystycznie.

4. Wzrost plonu ziarna pszenicy jarej pomiędzy poszczególnymi obiektami doświadczenia nie był równoznaczny ze zmniejszeniem się liczby chwastów.

5. Najniższą średnią liczbę oraz masę chwastów zaobserwowano w grupie, w której międzyplon został wysiany po podorywce, a pszenica wysiana technologią siewu bezpośredniego (S_D). Zastosowanie powyższych agrotechnik pozwoliło $\mathrm{w}$ największym stopniu ograniczyć zachwaszczenie łanu.

\section{Literatura / References}

Didon U.M.E., Kolseth A.-K., Widmark D., Persson P. 2014. Cover crop residues - effects on germination and early growth of annual weeds. Weed Science 62 (2): 294-302. DOI: 10.1614/WS-D-13-00117.1

Gawęda D. 2009. Wpływ międzyplonów ścierniskowych na zachwaszczenie jęczmienia jarego uprawianego w monokulturze. [The influence of stubble catch crops on weed infestation of spring barley grown in monoculture]. Fragmenta Agronomica 26 (1): 34-41.

Gawęda D., Kwiatkowski C. 2012. Wheat infestation of spring common weeds (Triticum aestivum L.) grown in monoculture depending on the cover crop and weed control method. [Zachwaszczenie formy jarej pszenicy zwyczajnej (Triticum aestivum L.) uprawianej w monokulturze w zależności od międzyplonu i sposobu odchwaszczania]. Acta Agrobotanica 65 (3): 119-126.

Gawęda D., Wesołowski M., Kwiatkowski C.A. 2014. Weed infestation of spring barley (Hordeum vulgare L.) depending on the cover crop and weed control method. [Zachwaszczenie jęczmienia jarego (Hordeum vulgare L.) w zależności od międzyplonu i sposobu odchwaszczania]. Acta Agrobotanica 67 (1): 77-84. DOI: 10.5586/aa.2014.007

Jaskulski D., Tomalak S., Rudnicki F. 2000. Regeneracja stanowiska po pszenicy ozimej dla jęczmienia jarego przez rośliny międzyplonu ścierniskowego. Zeszyty Problemowe Postępów Nauk Rolniczych 470: 49-57.

Kraska P., Pałys E. 2006. Zachwaszczenie łanu jęczmienia jarego w warunkach zróżnicowanych systemów uprawy roli oraz poziomów nawożenia i ochrony. [Weed infestation in canopy of spring barley in condition of different tillage systems and fertilization and plant protection levels]. Acta Agrobotanica 59 (2): 323-333.

Kwiatkowski C. 2004. Wpływ międzyplonu na plonowanie i zachwaszczenie jęczmienia jarego uprawianego w monokulturze. [The effect of intercrops on yields and weed infestation of spring barley cultivated in monoculture]. Annales Universitatis Mariae CurieSkłodowska, Sectio E, Agricultura 59 (2): 809-815. 
Kwiatkowski C., Wesołowski M., Stępień A. 2004. Bioróżnorodność chwastów w trzech odmianach jęczmienia jarego uprawianych $\mathrm{w}$ siedmiorocznej monokulturze $\mathrm{i}$ zmianowaniu. [Biodiversity of weeds in three cultivars of spring barley grown in seven-year monoculture and crop rotation]. Acta Scientiarum Polonorum, Agricultura 3 (2): 109-117.

Majchrzak L., Piechota T. 2014. Wpływ technologii uprawy na zachwaszczenie pszenicy jarej. [Influence of cultivation technology on spring wheat weed infestation]. Fragmenta Agronomica 31 (3): 94-101.

Parylak D., Zawieja J., Jędruszczak M., Stupnicka-Rodzynkiewicz E., Dąbkowska T., Snarska K. 2006. Wykorzystanie zasiewów mieszanych, właściwości odmian lub zjawiska allelopatii w ograniczaniu zachwaszczenia. [Use of the mixed crops, cultivar properties or allelopathy in weed control]. Progress in Plant Protection/Postępy w Ochronie Roślin 46 (1): 33-44.

Sekutowski T., Domaradzki K. 2009. Bioróżnorodność gatunkowa chwastów w monokulturze pszenicy ozimej w warunkach stosowania uproszczeń w uprawie roli. [Biodiversity of weed species in winter wheat monoculture caused by reduced of tillage]. Fragmenta Agronomica 26 (4): 166-169.

Skuterud R., Semb K., Saur J., Mygland S. 1996. Impact of reduced tillage on the weed flora in spring cereals. Norwegian Journal of Agricultural Sciences 10 (4): 519-532.

Tørresen K.S., Skuterud R. 2002. Plant protection in spring cereal production with reduced tillage. IV.: Changes in the weed flora and weed seedbank. Crop Protection 21 (3): 179-193. DOI: 10.1016/S0261-2194(01)00081-3

Woźniak A. 2011. Weed infestation of a spring wheat (Triticum aestivum L.) crop under the conditions of plough and ploughless tillage. [Zachwaszczenie łanu pszenicy jarej (Triticum aestivum L.) w warunkach płużnej i bezpłużnej uprawy roli]. Acta Agrobotanica 64 (3): 133-140.

Żuk-Gołaszewska K., Wanic M., Orzech K. 2019. The role of catch crops in field plant production - A review. Journal of Elementology 24 (2): 575-587. DOI: 10.5601/jelem.2018.23.3.1662 